\title{
Survey overlap impedes fossil hunters' study
}

Rex Dalton, San Diego

A dispute is simmering between Americanand Italian-led teams over access to one of the world's most promising hominid fossil fields.

The two groups are each feeling their way through research regulations in the East African state of Eritrea, which gained its independence from Ethiopia in 1993 and has since been attempting to open up its rich cultural heritage to scientific investigation.

The dispute is over the northern Danakil Depression, where rocky outcrops have brought fossils to the surface to reveal tantalizing clues of early hominids in the region (see E. Abbate et al. Nature 393, 458-460; 1998).

Since 1995, a team from the University of Florence, Italy, has been exploring a region around the hamlet of Buia, where a million-year-old hominid skull was found. But when the Italian team, led by Lorenzo Rook, returned earlier this month to begin new explorations there, they were told that their research permits would be delayed.

According to Rook, Eritrean officials blamed the delay on problems that had arisen last October during a field trip in the same region by a team led by Randall Susman of Stony Brook University in New York. The Italian researchers are also annoyed that Susman was covering territory where they had been previously working.

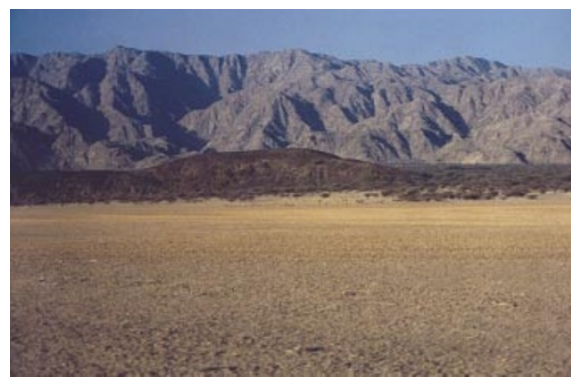

Disputed territory: the Danakil Depression, where two teams' explorations overlapped.

Such overlaps are frowned on by most physical anthropologists, but they are permitted by Eritrean regulations, which prohibit "exclusive" territorial concessions.

The field trip by Susman, a Stony Brook anatomist with 25 years' experience in functional-morphology research in Africa, has sparked unease in the Eritrean capital of Asmara. It has also caused ripples in San Francisco, home of the Leakey Foundation, which supports research into human origins and has provided US\$15,000 to pay for the expedition.

In Asmara, Eritrean government officials have suspended Susman's survey permit, after his October field trip had included a South African geologist not approved as a member of the team. Susman acknowledges that this was an "administrative mistake", saying it was an unintentional violation of regulations.
In San Francisco, Leakey Foundation officials criticized Susman for entering the Italian team's territory, when his grant award specifically stated that "the Leakey Foundation wishes to emphasize that your and the Italian team's study area should not overlap".

Clark Howell, chairman of the Leakey Foundation's scientific executive committee and a former professor of anthropology at the University of California, Berkeley, has suggested that Susman should return the grant to the foundation in light of the incident - but the full executive committee has declined to ask for such a refund.

Susman says that he tried hard to avoid the Italians' region, but ended up there because of inadequate maps, difficulties in securing Eritrean scientific assistance and confusion over the regulations. "I made every reasonable effort to prevent this from happening," he says, "but it was impossible to avoid."

Fossils collected on the expedition have been deposited at the Eritrean National Museum, Susman says. But Tewelde Medin Tecle, an Eritrean geologist who has worked with the Italian researchers, has accused Susman's team of harming the site by removing fossils and ancient tools. Susman denies this.

Late last week, Rook said that he hoped to leave soon for the field near Buia. "We are paying for the mistake someone else made," he says.

\section{Delegates nudge fusion project closer to reality}

David Cyranoski, Tokyo

International negotiators met in Tokyo last week to discuss plans for the construction of ITER, the proposed magnetic-fusion energy experiment.

Among the topics discussed by delegates from the European Union, Russia, Canada and Japan at the two-day negotiations were procedures for selecting a site for the experiment and for procuring equipment.

The United States, which is considering rejoining the project (see Nature 415, 247; 2002), did not take part in the negotiations. But Robert Goldston, director of the Princeton Plasma Physics Laboratory, the largest magnetic-fusion laboratory in the United States, did attend an associated symposium that was held to bolster public support for the project. "I hope the United States joins," he says.

Whether Japan itself will offer to host the experiment remains unclear. In a

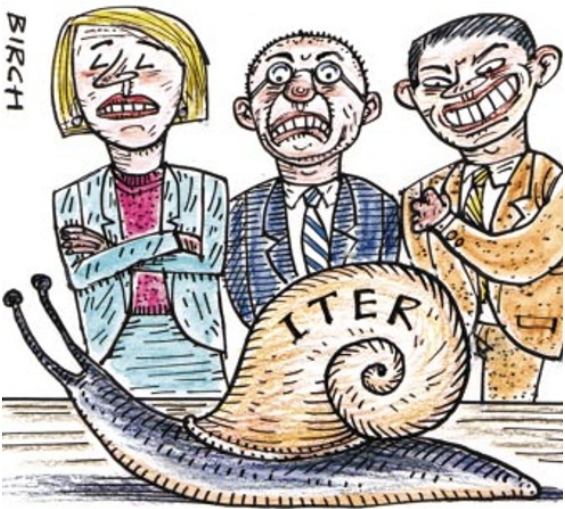

SNAIL RACING IN JAPAN.

preliminary report issued last December, the Council for Science and Technology Policy, Japan's highest scientific research body, reiterated its desire to host the project. The report said that this would cost Japan $¥ 700$ billion (US\$5 billion) over the first
10 years, for construction and operations. Japan's estimated cost of participation if the experiment is built elsewhere is $¥ 300$ billion.

Within Japan, public support for nuclear energy has recently weakened (see Nature 411,$729 ; 2001$ ), and anti-nuclear groups used the negotiations as an opportunity to raise concerns about ITER's safety and viability.

Japan's Ministry of Education, Science, Sports and Culture is still assessing two proposed sites for the facility. One of them, at Naka in Ibaraki, would be close to the Japan Atomic Energy Research Institute's existing nuclear-fusion facilities and quite close to Tokyo's main airport. The second site, at Rokkasho in Aomori, is on the northern tip of Japan's main island, where much of the country's nuclear waste is stored.

The ministry hopes to choose between the two sites before the next ITER meeting in Moscow on 19 March. 